В статье представлено семь моделей поведения клиентов онлайн-ретейла в условиях цифровой трансформации. Первая модель «Индивидуальное позиционирование» предполагает выбор товаров согласно их индивидуальным предпочтениям, изменяющимся с учетом цифровой трансформации. Вторая модель «Подражание» предполагает безоговорочное следование современным рыночным тенденциям. Модель «Использование цифрового контента» подразумевает предоставление пользователям качественного цифрового контента, который удовлетворит их потребности. Четвертая модель «Сотрудничество с другими клиентами и компанией через открытые платформы» позволяет клиентам достигать поставленных целей, информировать друг друга о товарах, работах, услугах, их преимуществах и недостатках. Вовлечение клиента в процесс создания продукта на первоначальной стадии формирует пятую модель - «Вовлеченность клиента». Шестая модель - модель поведения, предполагающая взаимодействие потребителей с целью выработки единого мнения относительно того или иного товара. Модель «Оперативный доступ и пользование» подразумевает определенное поведение пользователей, которое заключается в желании оперативно приобрести те или иные товары, услуги, работы. В статье автором разработаны стратегии развития онлайн-ретейла, соответствующие моделям поведения клиентов.

Кююевые слова: клиент, модель поведения клиентов, стратегия, онлайн-ретейл, цифровая трансформация.

\title{
MODELS OF ON-LINE RETAIL CLIENTS' BEHAVIOR IN CONDITIONS OF DIGITAL TRANSFORMATION
}

\author{
Il'ya S. Pushkin \\ Plekhanov Russian University of Economics, Moscow, Russia
}

The article shows 7 models of on-line retail clients' behavior in conditions of digital transformation. The 1st model 'Individual positioning' offers a choice of goods in accordance with their individual preferences changing with regard to digital transformation. The 2nd model 'Imitation' implies unconditional following the current market trends. The model 'The use of digital content' means supply of high-quality digital content, which can meet users' needs. The 4th model 'Cooperation with other clients and the company through open platforms' allows clients to achieve the set goals, to inform each other about goods, jobs, services, their advantages and disadvantages. The involvement of clients into the process of product development at the initial stage forms the 5th model - 'Client's involvement'. The 6 th model implies interaction with the customer in order to reach a single opinion concerning this or that product. The model 'Operative access and use' means a certain behavior of the customer, which shows a wish to get this or that product, service or job rather quickly. The author put forward strategies of developing online retail, which correspond to adequate models of clients' behavior.

Keywords: client, model of clients' behavior, strategy, on-line retailing, digital transformation.

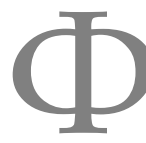

ормирование эффективных бизнес-моделей позволяет организовать цепочки создания ценности таким образом, чтобы их реализация максимизировала генерируемые денежные потоки. Однако такие цепочки подверже- 
ны воздействию факторов среды их функционирования, которые необходимо учитывать, анализировать и с учетом результатов такого анализа выбирать наилучшие варианты и направления деятельности.

Исполнение любых бизнес-моделей направлено на достижение целей, которые задают владельцы бизнеса, на преобразование компании согласно их видению, на повышение стоимости активов. Совокупность целей, показателей, позволяющих измерить уровень их достижения, мероприятий, направленных на достижение поставленных целей, формирует стратегию компании.

Стратегия развития онлайн-ретейла представляет собой видение владельцев бизнеса, набор целей, достижение которых позволит компании развиваться согласно такому видению, а также план мероприятий, направленных на достижение целей, реализация которых возможна за счет использования цифровых технологий.

В условиях цифровой трансформации стратегии онлайн-ретейла определяются исходя из моделей поведения клиентов. Рассмотрим семь таких моделей.

1. Индивидуальное позиционирование. Клиенты выбирают товары согласно их индивидуальным предпочтениям, которые с учетом цифровой трансформации становятся все более изысканными. Данная модель стала зарождаться благодаря активному формированию общества потребления. В XX в. спрос существенно превышал предложение, отсутствовал большой выбор товаров и зачастую потребители просто довольствовались наличием того, что есть на прилавках. Развитие процессов глобализации, появление Интернета, создание инновационных технологий способствовали увеличению производства и существенному росту предложения товаров, работ и услуг. Постепенно предложение стало превышать спрос, и потребовались инструменты, направленные не только на его правильную идентификацию, но и на формирование с целью навязывания потенциальным потребителям новых това- ров. Кроме того, многие товары стали доступны большинству покупателей, что для некоторых клиентов психологически тяжело воспринимается, они хотят выделяться, а для этого им нужен индивидуальный продукт. Соответственно, привлечение подобных клиентов требует мероприятий, направленных на удовлетворение их сильно индивидуализированных потребностей, что формирует стратегию удовлетворения индивидуальных потребностей. Примером реализации данной модели служит страница в социальной сети Facebook парфюмерной компании Lancome, на которой пользователям предоставляется возможность проанализировать применение продукции к их фотографиям.

2. Подражание. Модель предполагает безоговорочное следование современным рыночным тенденциям. В конце XX столетия зародилась серьезная конкурентная война между участниками рынка, в результате которой успешные игроки поглощают или подавляют более слабых. В результате сильные участники рынка смогли захватить большую его долю благодаря различным факторам: уникальным технологиям, эксклюзивному доступу к ресурсам, инновационному развитию и др. Такие компании стали управлять рынком, задавая определенные тренды. Доказательством этому могут служить очереди за смартфонами iPhone или в рестораны известных брендов. Клиент готов делать все, лишь бы следовать моде, что иногда приводит к трагическим последствиям. Например, в Китае подросток выбросился из окна, так как родители отказались покупать ему новый iPhone. В большинстве случаев многие потребители модных товаров не пользуются их полным функционалом (таким потребителям он просто не нужен), однако они готовы переплачивать, чтобы почувствовать себя в тренде. Организация таких трендов, развитие брендов и их правильное позиционирование, направленное на массовое привлечение покупателей, требуют реализации опреде- 
ленных мероприятий, которые формируют стратегию, создающую бренд.

3. Использование изифрового контента. Цифровые технологии позволяют создать качественный контент, обеспечивающий потребителей необходимой информацией о товарах, работах, услугах. Пользователи становятся все больше зависимыми от данного формата предоставления информации. До активного развития Интернета таким контентом служили цветные каталоги товаров и услуг, однако они не предоставляли всеобъемлющую информацию о продукции и потребители были вынуждены смотреть товар вживую в офлайнмагазине. Появление видеоканалов и создание видеороликов, на которых наглядно демонстрируются способы использования товара или оказания услуги, дают клиенту возможность получить всю необходимую информацию в любом месте, используя компьютер, планшет или телефон. Развитие социальной сети Instagram способствовало эффективной реализации данной модели поведения клиентов. Любой пользователь может посмотреть фото или видео о товаре, его преимуществах, альтернативах, прочитать отзывы, увидеть комментарии других потребителей. Такой подход формирует стратегию продвижения с помощью цифрового контента, что позволит компании вывести свою продукцию на рынок и информировать клиентов о ее преимуществах. Примером реализации данной модели может служить предоставление ограниченного бесплатного доступа к онлайн-курсам или программному обеспечению с целью привлечения клиентов и дальнейшей продажи полноценных версий.

4. Сотрудничество с другими клиентами u компанией. В цифровой эпохе клиенты сотрудничают друг с другом, используя различные открытые платформы, что позволяет им достигать поставленных целей, информировать друг друга о товарах, работах, услугах, их преимуществах и недостатках. Пользователи готовы объединяться и участвовать в проектах краудфандинга или краудсорсинга с целью получения желаемого результата. Если потребителям интересна идея и они хотят видеть ее реализованной в самые короткие сроки, они готовы приложить усилия и оказать поддержку автору такой идеи. Активное развитие данной модели поведения клиентов стало возможным благодаря появлению краудфандинговых и краудсорсинговых площадок. В 2000 г. в США появилась первая краудфандинговая площадка для музыки Artist Share. В России наибольшей популярностью пользуются такие площадки, как Kickstarter и Boomstarter. Краудфандинг и краудсорсинг поддерживают развитие стартапов и инновационных идей. Компании должны учитывать такую модель поведения клиентов и использовать ее для создания уникальных решений, которые будут позитивно восприняты рынком. Мероприятия, направленные на создание подобных решений, формируют стратегию, направленную на сотрудничество с клиентами.

5. Вовлеченность клиента. Модель предполагает вовлечение клиента в процесс создания продукта уже на первоначальной стадии. Производство продукции предполагает два варианта реализации цепочек создания ценности производителей: выталкивающие и втягивающие цепочки создания ценности. Реализация данной модели возможна при использовании втягивающей цепочки, при этом клиент принимает участие не только на этапе получения и согласования заказа, но и на других этапах, включая непосредственное производство. Эффективным инструментом реализации такой модели является методика SCRUM [7]. По мнению Дж. Сазерленда, SCRUM - набор принципов, согласно которым строится процесс создания продукта, позволяющий в фиксированные сроки предоставить клиенту требуемый результат. Такие сроки называются спринтами (итерации, в ходе которых создается определенный функционал). Впервые подход SCRUM был описан в статье «The new product development game» специалистами 
проектного управления Хиротака Такэути и Икудзиро Нонака. Они пояснили, что небольшие команды разнопрофильных специалистов справляются с проектами быстрее и достигают лучших результатов. Подробное описание метода SCRUM было представлено в книге Дж. Сазерленда «Scrum. Революционный метод управления проектами» [7]. Реализация этой модели поведения клиентов требует эффективной организации бизнес-процессов и достижения целей процессной перспективы, что формирует стратегию, направленную на взаимодействие с клиентом.

6. Согласование с другими клиентами. Модель предполагает взаимодействие потребителей с целью выработки единого мнения относительно того или иного товара. В цифровой эпохе данная модель реализуется благодаря использованию социальных сетей, мессенджеров, форумов, с помощью которых потребители обмениваются мнениями, комментариями. Например, один пользователь выкладывает фото с идеей и комментариями, а другие начинают активно ее поддерживать или, наоборот, отвергать. Обсуждение и рекомендации того или иного специалиста возможны благодаря профессиональным форумам. К примеру, если несколько клиентов остались довольны услугами определенного врача, то они рекомендуют его другим участникам обсуждения проблемы. Мероприятия, учитывающие данную модель, формируют стратегию, направленную на участие компании во взаимодействии потребителей. Компания может использовать цифровые инструменты для сбора данных в социальных сетях, где пользователи ведут открытые диалоги по поводу потребления определенной продукции. Кроме того, возможно эффективное взаимодействие с пользователями через социальные сети. Примером может служить «Ситибанк», успешно реагирующий на более $30 \%$ запросов клиентов с помощью Twitter.

7. Оперативный доступ и пользование. Модель подразумевает определенное по- ведение пользователей, которое заключается в желании оперативно приобрести те или иные товары, услуги, работы. Клиенты не готовы тратить время на то, чтобы ждать несколько месяцев определенный товар, им он нужен здесь и сейчас. В цифровой эпохе эффективной реализации данной модели способствует гибкая методология разработки agile. Agile - эффективное взаимодействие в команде с целью оперативного создания и вывода на рынок требуемого продукта. Появление данной методики связывают с выпущенным в США в 2001 г. Манифестом гибкой методологии разработки программного обеспечения (Agile Manifesto), который был согласован и подписан представителями таких методологий, как SCRUM, Adaptive software development и др. В Манифесте заложены следующие принципы:

- удовлетворение потребностей клиента за счет своевременной поставки продукта;

- вовлеченность заказчика в процесс разработки;

- мотивация участников разработки;

- самоорганизация с целью получения лучших характеристик продукта;

- поддержка постоянных темпов разработки;

- работающий продукт - лучший показатель измерения прогресса;

- постоянное совершенствование работы команды;

- простота работы;

- приветствие изменений требований даже в конце разработки;

- рекомендуемый метод передачи информации - личный разговор между участниками команды;

- постоянная адаптация к изменяющимся условиям.

Применение методики agile позволяет ускорить процессы создания и вывода продукции на рынок. Совместно с agile также может использоваться методика SCRUM, так как они не противоречат друг другу. Зачастую SCRUM относят к семейству agile. Соответственно, мероприятия, 
учитывающие данную модель поведения пользователей, формируют стратегию быстрого вывода продуктов/услуг на рынок.

В таблице представлены семь вышеописанных моделей поведения клиентов и со- ответствующие данным моделям стратегии компании, а также методики, технологии и инструменты, применяемые для их эффективной реализации.

\section{Модели поведения клиентов и соответствующие стратегии}

\begin{tabular}{|c|c|c|}
\hline Модель поведения клиентов & Стратегия & $\begin{array}{c}\text { Методики, технологии, } \\
\text { инструменты }\end{array}$ \\
\hline $\begin{array}{l}\text { Индивидуальное позиционирова- } \\
\text { ние }\end{array}$ & $\begin{array}{l}\text { Стратегия удовлетворения инди- } \\
\text { видуальных потребностей }\end{array}$ & $\begin{array}{l}\text { Втягивающие цепочки создания } \\
\text { ценности, директ-маркетинг }\end{array}$ \\
\hline Подражание & Стратегия, создающая бренд & $\begin{array}{l}\text { Инструменты маркетинга, рекла- } \\
\text { ма, социальные сети }\end{array}$ \\
\hline $\begin{array}{ll}\text { Использование цифрового кон- } \\
\text { тента }\end{array}$ & $\begin{array}{l}\text { Стратегия продвижения с помо- } \\
\text { щью цифрового контента }\end{array}$ & $\begin{array}{l}\text { Фото и видеоролики, видеообзо- } \\
\text { ры, дополненная реальность }\end{array}$ \\
\hline $\begin{array}{l}\text { Сотрудничество с другими клиен- } \\
\text { тами и компаниями }\end{array}$ & $\begin{array}{l}\text { Стратегия, направленная на со- } \\
\text { трудничество с клиентами }\end{array}$ & $\begin{array}{l}\text { Краудфандинговые и краудсор- } \\
\text { синговые площадки, социальные } \\
\text { сети, форумы }\end{array}$ \\
\hline сть клиента & $\begin{array}{l}\text { Стратегия, } \quad \text { направленная } \\
\text { взаимодействие с клиентом }\end{array}$ & $\begin{array}{l}\text { SCRUM, втягивающие цепочки } \\
\text { создания ценности }\end{array}$ \\
\hline $\begin{array}{l}\text { Согласование с другими клиента- } \\
\text { ми }\end{array}$ & $\begin{array}{l}\text { Стратегия, направленная на уча- } \\
\text { стие компании во взаимодействии } \\
\text { потребителей }\end{array}$ & $\begin{array}{l}\text { Социальные сети, мессенджеры, } \\
\text { форумы }\end{array}$ \\
\hline $\begin{array}{l}\text { Оперативный доступ и пользова- } \\
\text { ние }\end{array}$ & $\begin{array}{l}\text { Стратегия быстрого вывода про- } \\
\text { дуктов/услуг на рынок }\end{array}$ & $\begin{array}{l}\text { Социальные сети, мессенджеры, } \\
\text { форумы }\end{array}$ \\
\hline
\end{tabular}

Таким образом, развитие цифровых технологий существенно улучшает качество технологических платформ, обеспечи- вая клиентов быстрым беспрепятственным доступом к необходимым ресурсам и цифровому контенту.

\section{Список литературы}

1. Масленников В. В., Ляндау Ю. В., Калинина И. А., Трохов А. А. Моделирование владельческого управления бизнесом с учетом рисков экономической безопасности (на примере торговой деятельности) // Вестник Российского экономического университета имени Г. В. Плеханова. - 2018. - № 1 (97). - С. 123-131.

2. Мусатова Ж. Б. Влияние маркетинговой стратегии на эффективность и прибыльность компании // Вестник Российского экономического университета имени Г. В. Плеханова. - 2015. - № 1 (79). - С. 106-116.

3. Остервальдер А., Пинъе И. Построение бизнес-моделей. Настольная книга стратега и новатора. - М. : Альпина Паблишер, 2018.

4. Пихлер Р. Управление продуктом в Scrum. Agile-методы для вашего бизнеса. - М. : Манн, Иванов и Фербер, 2017.

5. Попенкова Д. К. Стратегии международных ретейлеров // Вестник Российского экономического университета имени Г. В. Плеханова. - 2017. - № 3 (93). - С. 120-126.

6. Роджерс Д. Цифровая трансформация. - М. : Точка, 2018.

7. Сазерленд Дж. Scrum. Революционный метод управления проектами. - М. : Манн, Иванов и Фербер, 2017. 


\section{References}

1. Maslennikov V. V., Lyandau Yu. V., Kalinina I. A., Trokhov A. A. Modelirovanie vladel'cheskogo upravleniya biznesom s uchetom riskov ekonomicheskoy bezopasnosti (na primere torgovoy deyatel'nosti) [Modeling Proprietary Management of Business with Regard to Risks of Economic Security (Illustrated by Trade Activity)]. Vestnik Rossiyskogo ekonomicheskogo universiteta imeni G. V. Plekhanova [Vestnik of the Plekhanov Russian University of Economics], 2018, No. 1 (97), pp. 123-131. (In Russ.).

2. Musatova Zh. B. Vliyanie marketingovoy strategii na effektivnost' i pribyl'nost' kompanii [The Impact of Marketing Strategy on Company Efficiency and Profitability]. Vestnik Rossiyskogo ekonomicheskogo universiteta imeni G. V. Plekhanova [Vestnik of the Plekhanov Russian University of Economics], 2015, No. 1 (79), pp. 106-116. (In Russ.).

3. Ostervalder A., Pinye I. Postroenie biznes-modeley. Nastol'naya kniga stratega i novatora [Creation of Business Models. Reference Book of the Strategist and Innovator]. Moscow, Alpina Pablisher, 2018. (In Russ.).

4. Pichler R. Upravlenie produktom v Scrum. Agile-metody dlya vashego biznesa [Product Management in Scrum. Agile-Methods for your Business]. Moscow, Mann, Ivanov i Ferber, 2017. (In Russ.).

5. Popenkova D. K. Strategii mezhdunarodnykh reteylerov [Strategies of International Retailers]. Vestnik Rossiyskogo ekonomicheskogo universiteta imeni G. V. Plekhanova [Vestnik of the Plekhanov Russian University of Economics], 2017, No. 3 (93), pp. 120-126. (In Russ.).

6. Rogers D. Tsifrovaya transformatsiya [Digital Transformation]. Moscow, Tochka, 2018. (In Russ.).

7. Sazerland G. Scrum. Revolyutsionnyy metod upravleniya proektami [Scrum. Revolutionary Method of Project Management]. Moscow, Mann, Ivanov i Ferber, 2017. (In Russ.).

\section{Сведения об авторе}

\section{Илья Сергеевич Пушкин}

аспирант кафедры теории менеджмента

и бизнес-технологий

РЭУ им. Г. В. Плеханова.

Адрес: ФГБОУ ВО «Российский

экономический университет имени

Г. В. Плеханова», 117997, Москва,

Стремянный пер., д. 36.

E-mail: kaf.tmbt@rea.ru

\section{Information about the author}

\section{Il'ya S. Pushkin}

Post-Graduate Student of the Department for Theory of Management and

Business-Technologies of the PRUE.

Address: Plekhanov Russian University

of Economics, 36 Stremyanny Lane,

Moscow, 117997,

Russian Federation.

E-mail: kaf.tmbt@rea.ru 